\title{
Synthesis of Functionalized Cyclopentene Derivatives from Vinyldiazo Compounds and Vinylazides through Sequential Copper-Promoted [3+2] Cycloaddition/Azide Rearrangement
}

\author{
Enol López, ${ }^{[a]}$ and Luis A. López ${ }^{*[a]}$ \\ Dedication ((optional))
}

\begin{abstract}
The reaction of vinylazides with alkenyldiazo compounds in the presence of $\left[\mathrm{Cu}\left(\mathrm{CH}_{3} \mathrm{CN}\right)_{4}\right]\left[\mathrm{BF}_{4}\right]$ provided cyclopentene derivatives retaining the azide functionality. This process would involve a sequence comprising: 1) decomposition of the diazo component with generation of a copper alkenylcarbene species; 2) stepwise regioselective [3+2] cycloaddition; 3) allylic azide rearrangement. A broad range of substrates is compatible with this protocol. We have also shown that azide-containing cycloadducts can be efficiently converted to the corresponding amine and triazole derivatives.
\end{abstract}

Vinylazides have become prominent building blocks for organic synthesis. ${ }^{[1]}$ The synergistic combination of chemical properties of the two conjugated functional groups (azide and alkene) present in their structure provides a rich and varied reactivity that has been exploited in a wealth of synthetically useful transformations. Most of the synthetic applications based on vinylazides rely on a facile release of molecular nitrogen by heating or photolysis with generation of vinylnitrene intermediates or highly strained three-membered $2 \mathrm{H}$-azirines. This general reactivity pattern, in which the vinylazide acts as a three-atom C-C-N synthon, has been extensively studied over the years and has found manifold applications in the synthesis of many valuable nitrogen heterocyclic compounds. In contrast, processes in which the azide function is retained in the final products are rather unusual. Nevertheless, these procedures would be highly desirable from a synthetic point of view because azides can be easily transformed into a range of nitrogen-based functional groups through well-established methodologies, thus providing access to a wide variety of nitrogen-containing compounds.

On the other hand, in the last years our group and others have actively pursued the development of new synthetic methodologies based on the reactivity of coinage metal alkenylcarbene species generated from stabilized vinyldiazo compounds. ${ }^{[2]}$ As a continuation of our ongoing interest in this topic, herein we report the copper(I)-promoted reaction of stabilized vinyldiazo compounds with vinylazides leading to functionalized cyclopentene derivatives arising from a formal [3+2] cycloaddition/allylic azide rearrangement sequence.

[a] E. López, Dr. L. A. López

Departmento de Química Orgánica e Inorgánica and Instituto Universitario de Química Organometálica "Enrique Moles" Universidad de Oviedo

Julián Clavería 8, 33006-Oviedo (Spain)

E-mail: lalg@uniovi.es

Supporting information for this article is given via a link at the end of the document.((Please delete this text if not appropriate))
Interestingly, these results stand in marked contrast to those previously found by Liu and co-workers in the reaction of vinylazides with gold alkenylcarbene species generated from propargylic esters, that led to buta-1,3-dien-2-yl esters (Scheme 1). ${ }^{[3]}$ Prior to our study, that was the only contribution on the reactivity of vinylazides toward alkenylcarbene intermediates. ${ }^{[4]}$

\section{Liu's work ${ }^{[3]}$}

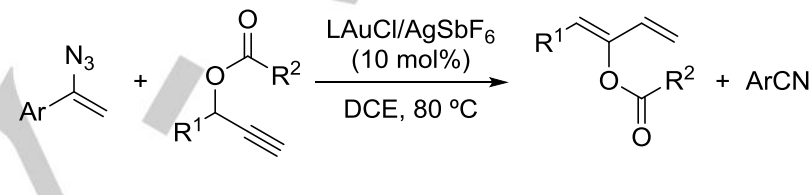

This work

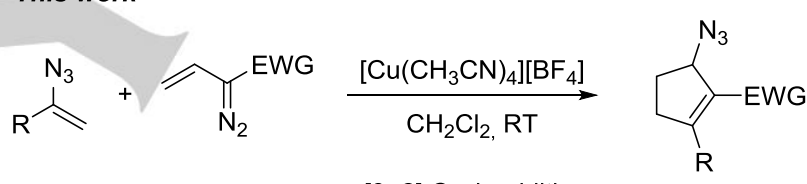

- [3+2] Cycloaddition - Azide rearrangement

Scheme 1. Reactivity of vinylazides toward alkenylcarbene precursors.

For our exploratory studies we selected readily available ethyl 2 diazobut-3-enoate (1a) and $\alpha$-azidostyrene (2a) as substrates and a series of transition metal catalysts $(5 \mathrm{~mol} \%)$ in dichloromethane as solvent at room temperature (Table 1, see the Supporting Information for full details on the screening study). Our initial screening revealed that gold complexes (entries 1-3), which proved to be competent catalysts in several recent transformations involving stabilized vinyldiazo compounds, ${ }^{[5]}$ failed to afford any coupling product in the reaction of $\mathbf{1 a}$ and $\mathbf{2 a}$. A similar outcome was also found when the reaction was performed in the presence of $\mathrm{Rh}_{2}(\mathrm{OAc})_{4}$ or $\mathrm{AgSbF}_{6}$ (entries 4 and 5). Next, we evaluated a series of copper complexes (entries 6-11). It should be noted that although copper catalysts have been extensively studied in the decomposition of simple diazo compounds, their use in transformations involving vinyldiazo compounds is mainly restricted to enoldiazo acetates. $^{[6,7]}$ To our delight, various copper complexes proved capable of promoting the formation of cyclopentene derivative 3a. Among them, $\left[\mathrm{Cu}\left(\mathrm{CH}_{3} \mathrm{CN}\right)_{4}\right]\left[\mathrm{BF}_{4}\right]$ was found to be the most effective, although cycloadduct 3 a was obtained in a yield of $27 \%$ after 3 days at room temperature (entry 11 ). Noteworthy, the yield increased to $81 \%$ when the reaction was run with 0.5 equivalents of the copper complex (entry 13). 
Notably, this formal [3+2] carbocyclization reaction takes place with complete regioselectivity.

Taking into account that azides can serve as masked primary amines, compound $3 \mathbf{a}$ can be regarded as an orthogonally protected $\beta$-aminoacid derivative. In this context, it should be mentioned that conformationally constrained carbocyclic $\beta$-amino acids are important building blocks in organic and peptide synthesis and some of them display important pharmacological properties. ${ }^{[8]}$

Table 1. Reaction of vinyldiazo compound $\mathbf{1 a}$ and vinylazide $\mathbf{2 a}$ : Summary of catalyst screening.

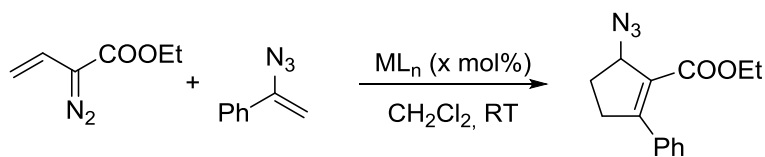

$3 a$

\begin{tabular}{|c|c|c|c|}
\hline Entry & $M L_{n}$ & $x$ & $3 \mathbf{a}^{[a]}(\%)$ \\
\hline 1 & {$[\mathrm{Au}(\mathrm{IPr})(\mathrm{MeCN})]\left[\mathrm{SbF}_{6}\right]$} & 5 & - \\
\hline $2^{[\mathrm{b}]}$ & $(\mathrm{ArOP})_{3} \mathrm{AuNTf}_{2}$ & 5 & - \\
\hline $3^{[c]}$ & JohnPhosAuNTf 2 & 5 & - \\
\hline 4 & $\mathrm{Rh}_{2}(\mathrm{OAc})_{4}$ & 5 & - \\
\hline 5 & $\mathrm{AgSbF}_{6}$ & 5 & - \\
\hline 6 & $\mathrm{Cu}(\mathrm{acac})_{2}$ & 5 & - \\
\hline 7 & $\mathrm{CuBr}$ & 5 & - \\
\hline 8 & Cul & 5 & - \\
\hline 9 & {$[\mathrm{Cu}(\mathrm{OTf})]_{2} \mathrm{C}_{6} \mathrm{H}_{6}$} & 5 & 10 \\
\hline 10 & {$\left[\mathrm{Cu}\left(\mathrm{CH}_{3} \mathrm{CN}\right)_{4}\right]\left[\mathrm{PF}_{6}\right]$} & 5 & 22 \\
\hline 11 & {$\left[\mathrm{Cu}\left(\mathrm{CH}_{3} \mathrm{CN}\right)_{4}\right]\left[\mathrm{BF}_{4}\right]$} & 5 & 27 \\
\hline 12 & {$\left[\mathrm{Cu}\left(\mathrm{CH}_{3} \mathrm{CN}\right)_{4}\right]\left[\mathrm{BF}_{4}\right]$} & 20 & 60 \\
\hline 13 & {$\left[\mathrm{Cu}\left(\mathrm{CH}_{3} \mathrm{CN}\right)_{4}\right]\left[\mathrm{BF}_{4}\right]$} & 50 & 81 \\
\hline
\end{tabular}

[a] Isolated yields. [b] $\mathrm{Ar}=2,4-{ }^{t} \mathrm{Bu}_{2} \mathrm{C}_{4} \mathrm{H}_{3}$. [c] JohnPhos $=2$-(di-tertbutylphosphino)biphenyl.

With suitable reaction conditions in hand, we turned our attention to examine the scope of this copper(I)-promoted transformation (Table 2).

First, we examined the variation of the diazo partner. As expected, the nature of the ester substituent has little impact on the reaction outcome. Thus, reaction of benzyl 2-diazobut-3enoate (1b; $R^{1}=R^{2}=H$, EWG $=$ COOBn) and vinylazide 2a afforded the corresponding cycloadduct $\mathbf{3 b}$ nearly quantitatively. Likewise, the use of tert-butyl substituted vinyldiazo compound (1c; $R^{1}=R^{2}=H$, EWG $=$ COO $^{t} \mathrm{Bu}$ ) led to expected cycloadduct $3 c$ in $70 \%$ yield.
Table 2. Scope of the Copper(I)-promoted [3+2] cycloaddition/allylic azide rearrangement of stabilized vinyldiazo derivatives $\mathbf{1}$ and vinylazides $2 .{ }^{[a, b]}$

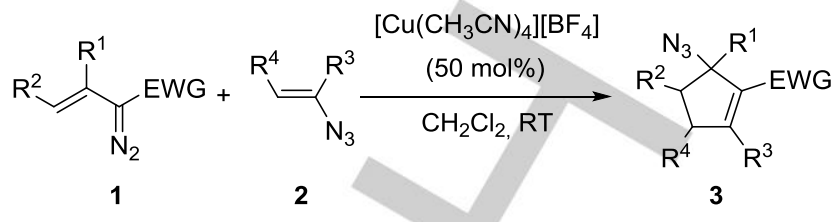<smiles>[N]C1CCC(c2ccccc2)=C1C(=O)Oc1ccccc1</smiles>

3b $(97 \%)$<smiles>CC(=O)C1=C(c2ccccc2)CCC1(C)N</smiles>

$\mathrm{Ph}$

$$
3 \text { e }(24 \%)
$$

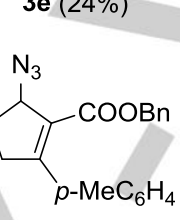

3h (86\%)<smiles>CCOC(=O)OC1=C(C(=O)OCC)C(N)CC1</smiles>

3k $(70 \%)$<smiles>CCCCOC(=O)C1=C(C(=O)OCCC)C(C)CC1N</smiles>

3n $(66 \%)$<smiles>CCOC(=O)C1=C(OOc2ccccc2)CCC1N</smiles>

$3 q(23 \%)$<smiles>CCOC(=O)C1=C([NH+]([O-])c2ccccc2)CCC1N</smiles>

$3 t(86 \%)^{[e]}$

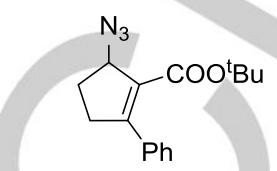

3c $(70 \%)$<smiles>COC(=O)C1=C(c2ccccc2)CC(c2ccccc2)C1N</smiles>

$3 f(40 \%)^{[d]}$<smiles>CCCCOC(=O)C1=C(OCCC)CCC1N</smiles>

$3 \mathbf{i}(58 \%)$<smiles>CCOC(=O)C1=C(OCC)CCC1N</smiles>

3I $(79 \%)$<smiles>CCCCOC1=C(C(=O)OCC)C(N)CC1</smiles>

3o $(74 \%)$<smiles>[CH]=[N+]C1CCC(N)=C1C(=O)OCC</smiles>

3r $(78 \%)$<smiles>CCOC(=O)C1=C(C)CCC1N</smiles>

3u $(25 \%)$<smiles>CCOC(=O)C1=C(c2ccccc2)CCC1(C)N</smiles>

3d $(32 \%)^{[\mathrm{c}]}$

$\mathrm{N}_{3}$<smiles>CCOC(=O)C1=C(OCC)CCC1O</smiles>

3 g $(79 \%)$<smiles>CCOC(=O)C1=C(Pc2ccccc2)CCC1N</smiles>

3j (66\%)<smiles>NC1CCC(OCCCCCCCCCCCOc2ccccc2)=C1C(=O)O</smiles>

3 m $(81 \%)$<smiles>CCCCOC1=C(C(=O)OCC)C(N)CC1</smiles>

$3 p(78 \%)$<smiles>CCOC(=O)C1=C(OCC)CCC1N</smiles>

3s $(23 \%)$<smiles>CCOC(=O)C1=C(c2ccccc2)C(C)CC1N</smiles>

$3 v(44 \%)^{[f]}$ [a] Reaction conditions: 1 (0.15 mmol), $2(0.45 \mathrm{mmol}),\left[\mathrm{Cu}\left(\mathrm{CH}_{3} \mathrm{CN}\right)_{4}\right]\left[\mathrm{BF}_{4}\right](50$ mol\%), $\mathrm{CH}_{2} \mathrm{Cl}_{2}, \mathrm{RT}$. [b] The reported yields are those of the products isolated after column chromatography. [c] Along with minor amounts of a isomeric product (See the Supporting Information for details). [d] A 2:1 mixture of cis/trans isomers was formed. Combined isolated yield of both isomers. [e] $\mathrm{Naph}=2$-naphthyl. [f] A 4:1 mixture of trans/cis isomers was isolated. 
The use of vinyldiazo compounds substituted at the vinyl moiety proved more challenging. For example, the use of a vinyldiazo compound with an alkyl group at the $C \beta$ atom $\left(\mathbf{1 d} ; R^{1}=M e ; R^{2}=\right.$ $\mathrm{H}, \mathrm{EWG}=\mathrm{COOEt}$ ) provided the corresponding cycloadduct $\mathbf{3 d}$, albeit in a modest yield (32\% isolated yield). Similarly, treatment of diazoketone 1e $\left(R^{1}=\mathrm{Me} ; \mathrm{R}^{2}=\mathrm{H}, \mathrm{EWG}=\mathrm{COMe}\right)$ with vinylazide $\mathbf{2 a}$ under the above reaction conditions produced cycloadduct $3 e$ in low yield. On the other hand, reaction with methyl (E)-2-diazo-4-phenylbut-3-enoate $\left(\mathbf{1 f}, \mathrm{R}^{1}=\mathrm{H} ; \mathrm{R}^{2}=\mathrm{Ph}\right.$, $E W G=C O O M e$ ) resulted in the formation of azide derivative $3 e$ in moderate yield and selectivity.

Regarding the vinylazide partner, the process was found to tolerate a wide range of substitution. Thus, an array of aryl substituted vinylazides were found to be viable substrates in this transformation. For example, vinylazides with electron-rich aromatic groups were well tolerated delivering the expected cyclic products $\mathbf{3 g}-\mathbf{k}$ in good yields (58-86\%). Aryl vinylazides bearing halogen atoms at the para-position were also well suited for this transformation furnishing the desired functionalized cyclopentene derivatives $\mathbf{3} \mathbf{I} \mathbf{p}$ in good yields. In contrast, a vinylazide with a strong electron-withdrawing nitro group exhibited very low reactivity affording the corresponding cyclopentene derivative $\mathbf{3 q}$ in lower yield.

Substitution at the meta-position of the aromatic ring of the aryl vinylazide produced the corresponding cyclopentene derivative $\mathbf{3 r}$ without noticeable erosion in yield (compare products $\mathbf{3 g}$ and $\mathbf{3 r}$ ). Conversely, the use of an aryl vinylazide bearing a substituent at the position ortho provided the corresponding product 3 s in lower yield ( $23 \%$ isolated yield).

Besides phenyl substituted vinylazides, the transformation tolerated the use of those featuring polycyclic aromatic groups as illustrated by the formation of naphthyl-containing cycloadduct 3t in good yield. Alkyl substituted vinylazides also provided the corresponding cyclopentene derivative resulting from a [3+2] cyclization/rearrangement sequence, albeit in lower yield (cyclopentene $3 \mathbf{u}, 25 \%$ ).

Finally, this copper-promoted transformation tolerated additional substitution of the aryl vinylazide at the $\beta$-position as demonstrated by the formation of cyclopentene $3 \mathbf{v}$ in moderate yield and selectivity.

The structure of compounds $\mathbf{3}$ was ascertained by NMR spectroscopic methods (including bidimensional experiments). Moreover, an X-ray structure analysis of cycloadduct $\mathbf{3 j}$ unambiguously confirmed the proposed structure. ${ }^{[9]}$

Based on previous reports on metal-promoted transformations of vinyldiazo compounds, a plausible mechanism for this transformation is depicted in Scheme 2. Initial reaction of the vinyldiazo compound with the copper(I) complex would form the copper(I) alkenylcarbene species I, which then would evolve to intermediate II, behaving in this transformation the vinylazide as an enamine-type nucleophile towards the electrophilic vinylogous position of the alkenylcarbene intermediate. ${ }^{[10-12]}$ Subsequent cyclization would generate the $[3+2]$ cycloadduct intermediate III, which would evolve to the final products through an allylic rearrangement of the azide function. ${ }^{[13-15]}$ The complete selectivity found in this $[3,3]$-sigmatropic isomerization (preference of $\mathbf{3}$ over its isomeric form III) is noteworthy because it has been reported that this rearrangement generally gives rise to mixtures of allylic isomers that interconvert at room temperature. Very likely, in our case the most substituted alkene (isomer 3) would be thermodynamically favoured. ${ }^{[16]}$ At present, we cannot establish whether the copper complex plays or not any role in the rearrangement reaction.

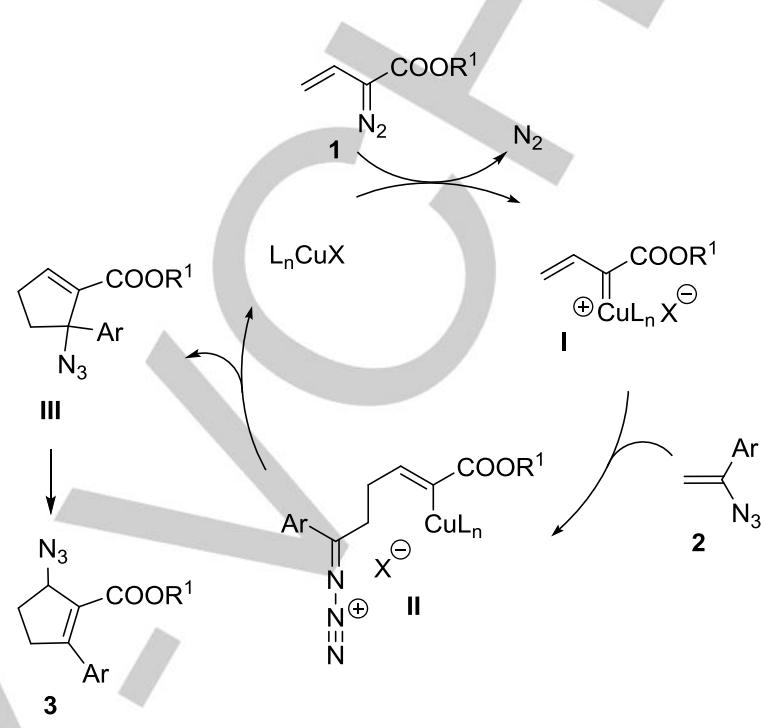

Scheme 2. Mechanistic rationale for the formation of cyclopentene derivatives 3.

Next, taking cyclopentene derivative $\mathbf{3 b}$ as a model substrate, several options for further elaboration of adducts based on wellestablished azide chemistry were evaluated (Scheme 3). Thus, when $\mathbf{3 b}$ was subjected to conventional Staudinger reaction conditions $\left(\mathrm{Ph}_{3} \mathrm{P}, \mathrm{THF} / \mathrm{H}_{2} \mathrm{O}, 50^{\circ} \mathrm{C}\right)$ the amino derivative 4 was obtained in $90 \%$ yield after chromatographic purification. On the other hand, an azide-alkyne click reaction furnishing triazole derivative $\mathbf{5}$ in moderate yield was also implemented.

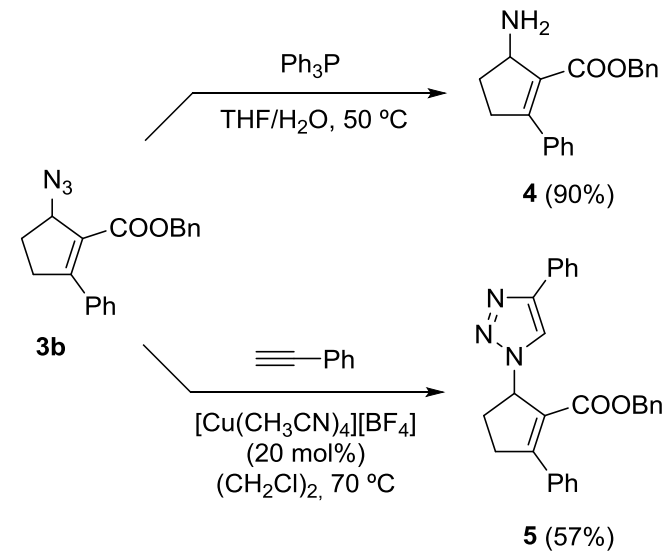

Scheme 3. Further elaboration of adduct $\mathbf{3 b}$

Triazole derivative $\mathbf{5}$ was also available through a one-pot procedure without isolation of cycloadduct $\mathbf{3 b}$ (Scheme 4). Thus, initial treatment of benzyl 2-diazo-2-phenylacetate (1b) with $\alpha$ - 
azidostyrene (2a) in the presence of the copper complex in dichloromethane, followed by addition of phenylacetylene furnished the target triazole derivative $\mathbf{5}$ in moderate yield after chromatography.

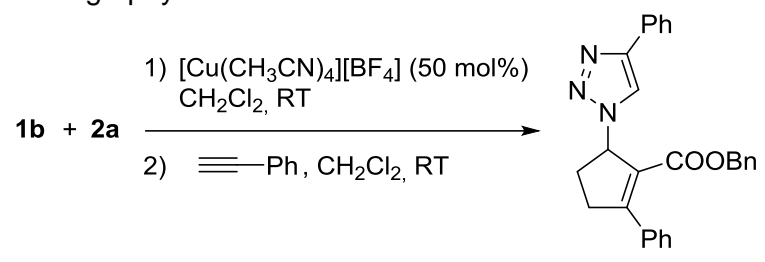

$5(53 \%)$

Scheme 4. One-pot synthesis of triazole derivative $\mathbf{5}$.

In summary, we have developed an efficient copper-mediated [3+2] cycloaddition process of vinyldiazo compounds and vinylazides, and it provides access to densely functionalized cyclopentene derivatives otherwise difficult-to-access. The observed reactivity pattern relies on the initial generation of a copper(I) alkenylcarbene intermediate, subsequent formal [3+2] cyclization and final allylic azide rearrangement. In contrast to many metal-promoted synthetic transformations involving vinylazides, in this transformation the azide function is maintained in the final cycloadducts, which enables many synthetic opportunities in the preparation of valuable nitrogencontaining carbocyclic structures. Additional features of our protocol are the availability of the required starting materials and catalyst and the synthetically useful yields. Follow-up research on the synthetic usefulness of the functionalized cyclopentene derivatives is currently under way in our group.

\section{Acknowledgements}

Financial support from Ministerio de Economía y Competitividad (MINECO, grant CTQ2013-41511-P), Agencia Estatal de Investigación (AEI) and Fondo Europeo de Desarrollo Regional (FEDER) (grant CTQ2016-76840-R) and Principado de Asturias (grant GRUPIN14-013) is gratefully acknowledged. E. L. thanks the Principado de Asturias for a predoctoral grant (Severo Ochoa Program). We thank Prof. J. M. González for interesting discussions. We are also grateful to Dr. F. J. González and Dr. J. Borge for their assistance with DFT calculations and X-ray data, respectively.

Keywords: Azides • Copper • (3+2) Cycloaddition • Cyclopentenes $\cdot$ Diazocompounds

[1] For recent reviews on the synthetic applications of vinylazides, see: a) B. Hu, S. G. DiMagno, Org. Biomol. Chem. 2015, 13, 3844-3855; b) S. Chiba, Synlett, 2012, 23, 21-44; c) N. Jung, S. Bräse, Angew. Chem. 2012, 124, 12335-12337; Angew. Chem. Int. Ed. 2012, 51, 12169 12171.

[2] For a comprehensive review covering recent advances in coinage catalyzed transformations of stabilized vinyldiazo compounds, see: $\mathrm{E}$.
López, S. González-Pelayo, L. A. López, Chem. Rec. 2017, DOI: 10.1002/trc.201600099.

[3] S. B. Wagh, R.-S. Liu, Chem. Commun. 2015, 51, 15462-15464.

[4] The synthesis of $\beta$-azidocyclopropane esters by cyclopropanation of vinylazides with aryldiazo esters in the presence of dirhodium catalysts had been reported: P. Gu, Y. Su, X.-P. Wu, J. Sun, W. Liu, P. Xue, R Li, Org. Lett. 2012, 14, 2246-2249.

[5] For a selection of gold-catalyzed transformations of vinyldiazo compounds, see: a) C. Zhu, G. Xu, J. Sun, Angew. Chem. 2016, 128, 12046-12050; Angew. Chem. Int. Ed. 2016, 55, 11867-11871; b) E. López, G. Lonzi, J. González, L. A. López, Chem. Commun. 2016, 52, 9398-9401; c) E. López, J. González, L. A. López, Adv. Synth. Catal. 2016, 358, 1428-1432; d) V. V. Pagar, R.-S. Liu, Angew. Chem. 2015 127, 5005-5008; Angew. Chem. Int. Ed. 2015, 54, 4923-4926; e) G. Xu, C. Zhu, W. Gu, J. Li, J. Sun, Angew. Chem. 2015, 127, 897-901; Angew. Chem. Int. Ed. 2015, 54, 883-887; f) E. López, G. Lonzi, L. A. López, Organometallics, 2014, 33, 5924-5927; g) D. Zhang, G. Xu, D. Ding, C. Zhu, J. Li, J. Sun, Angew. Chem. 2014, 126, 11250-11254; Angew. Chem. Int. Ed. 2014, 53, 11070-11074; h) J. F. Briones, H. M. L. Davies, J. Am. Chem. Soc. 2013, 135, 13314-13317; i) G. Lonzi, L. A. López, Adv. Synth. Catal. 2013, 355, 1948-1954; j) V. V. Pagar, A. M. Jadhav, R.-S. Liu, J. Org. Chem. 2013, 78, 5711-5716; k) A. M. Jadhav, V. V. Pagar, R.-S. Liu, Angew. Chem. 2012, 124, 11979-11983; Angew. Chem. Int. Ed. 2012, 51, 11809-11813; I) J. Barluenga, G. Lonzi, M. Tomás, L. A. López, Chem. Eur. J. 2013, 19, 1573-1576; m) V. V. Pagar, A. M. Jadhav, R.-S. Liu, J. Am. Chem. Soc. 2011, 133, 2072820731.

[6] For recent reviews on metal-catalyzed transformations of enoldiazoacetate derivatives, see: a) X.-F. Xu, M. P. Doyle, Chin. Chem. Lett. 2015, 26, 227-232; b) X. Xu, M. P. Doyle, Acc. Chem. Res. 2014, 47, 1396-1405.

[7] For a notable exception, see: J. Barluenga, G. Lonzi, L. Riesgo, L. A López, M. Tomás, J. Am. Chem. Soc. 2010, 132, 13200-13202.

[8] For a recent review on the synthesis of carbocyclic $\beta$-aminocarboxylic acids, see: L. Kiss, F. Fülöp, Chem. Rev. 2014, 114, 1116-1169.

[9] CCDC $1536433(\mathbf{3 j})$ contains the supplementary crystallographic data for this paper. These data are provided free of charge by The Cambridge Crystallographic Data Centre.

[10] For a related process involving initial formation of copper alkenylcarbene intermediates and subsequent nucleophilic attack to the vinylogous position, see reference [7].

[11] For additional examples of vinylogous reactivity of vinyldiazo compounds, see reference [5].

[12] For a related rhodium-catalyzed [3+2] cycloaddition of enecarbamates and enoldiazoacetates, see: Y. Deng, M. V. Yglesias, H. Arman, M. P. Doyle, Angew. Chem. 2016, 128, 10262-10266; Angew. Chem. Int. Ed. 2016, 55, 10108-10112;

[13] For a seminal report on this rearrangement of allylic azides, usually referred as Winstein rearrangement, see: A. Gagneux, S. Winstein, W. G. Young, J. Am. Chem. Soc. 1960, 82, 5956-5957.

[14] Selected reports of allylic azide isomerizations: a) A. K. Feldman, B. Colasson, K. B. Sharpless, V. V. Fokin, J. Am. Chem. Soc. 2005, 127, 13444-13445; b) S. Lauzon, F. Tremblay, D. Gagnon, C. Godbout, C. Chabot, C. Mercier-Shanks, S. Perreault, H. DeSève, C. Spino, J. Org Chem. 2008, 73, 6239-6250; c) R. Liu, O. Gutierrea, D. J. Tantillo, J. Aubé, J. Am. Chem. Soc. 2012, 134, 6528-6531; d) R. H. Vekariya, R Liu, J. Aubé, Org. Lett. 2014, 16, 1844-1847; e) L. Moynihan, R. Chadda, P. McArdle, P. V. Murphy, Org. Lett. 2015, 17, 6226-6229.

[15] An alternative mechanism involving a cyclopropanation of the vinylazide (see reference [4])/ring expansion/azide rearrangement cannot be completely ruled out.

[16] The geometries of cycloadduct $\mathbf{3 a}$ and the isomeric cyclopentene derivative Illa were fully optimized at the B3LYP/6-31G* level of theory. From these calculations, $3 \mathbf{a}$ is predicted to be $5.0 \mathrm{kcal} \mathrm{mol}^{-1}$ more stable than Illa. 


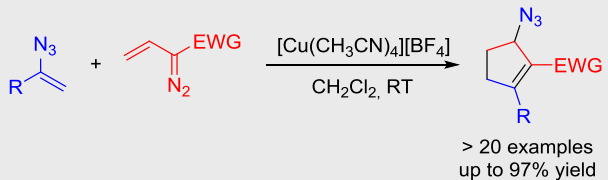

$2 x($ vinyl) $=3+2$. The copper-promoted reaction of vinylazides and vinyldiazo compounds provides a convenient route to azide-containing cyclopent-1-enecarboxylic acid derivatives. This transformation would involve initial generation of a copper alkenylcarbene species, which would evolve through a [3+2]

cycloaddition/allylic azide rearrangement sequence. Further elaboration of the azide functional group allowed for the synthesis of new nitrogen-containing carbocycles.
Enol López and Luis A. López*

Page No. - Page No.

Synthesis of Functionalized

Cyclopentene Derivatives from

Vinyldiazo Compounds and

Vinylazides through Sequential

Copper-Promoted [3+2]

Cycloaddition/Azide Rearrangement 